\title{
Managing workplace bullying
}

\author{
Fapohunda, Tinuke. M.
}

Department of Industrial Relations and Public Administration, Lagos State University Ojo, Nigeria

Email address:

tkfap@yahoo.com

\section{To cite this article:}

Fapohunda, T. M.. Managing Workplace Bullying. Journal of Human Resource Management. Vol. 1, No. 3, 2013, pp. 39-47. doi: $10.11648 /$ j.jhrm.20130103.11

\begin{abstract}
Workplace bullying is attracting increasing recognition and is an issue of concern for human resource managers and other actors in employment relations. This paper explores the concept of workplace bullying to determine its exact nature, features, sources, types, tactics and consequences of workplace bullying. It also examines how to deal with workplace bullying. The study had 280 participants selected from different organizations in the education, finance, communications and health sectors in Lagos Nigeria. Four hypotheses were tested on the relationship between work place bullying and organizational responses and attitudes, organization climate, gender and the self esteem. It found a significant relationship between gender and workplace bullying. Women tend to be more workplace bullies than men and have greater risks of becoming targets. There was a significant relationship between organizational attitudes and responses and the willingness of workers to report workplace bullying. A significant relationship was found between perceived organization culture and level of workplace bullying. Also there was a significant relationship between self esteem and workplace bullying. Victims of workplace bullying often exhibit lower levels of self-esteem and feel that their personalities caused them to be bullied.
\end{abstract}

Keywords: Managing, Workplace, Bullying

\section{Introduction}

Workplace bullying is an important problem in the workplace which is attracting increasing recognition and has become an issue of concern for human resource practitioners, management, workers and all actors in employment relations. While bullying occurs regularly within the workplace, victims tend to be apprehensive about reporting it due to the difficulties often associated with proving it. Workplace bullies generally use words and actions to intimidate their victims. A workplace bully may be a boss or co-worker or even subordinate. Workplace bullying can take shape in many unidentified forms like being forced to stay late, being given extra work compared with the amount colleagues are given, not being allowed to take holidays, not believed if sick leave is taken, and not getting a fair increase in salary.

It is a form of harassment which is very unpleasant and constitutes one of the most difficult to control aspects of employment relations with high costs to both employees and the organization. Workplace bullying is now a dilemma that is too expensive to ignore. Its increased recognition highlights the need for review of workplace policies, and grievance and mediation procedures aimed at ensuring that all employees are aware that workplace bullying is a form of harassment and will not be accepted or tolerated. Bullying in the workplace is a problem that is more common than most people think. Bullying can create a hostile work environment, which makes people miserable and hurts work productivity. The Workplace Bullying Institute defines workplace bullying as repeated, healthharming mistreatment of one or more persons by one or more perpetrators. Workplace bullying, once a condition suffered in silence, has garnered widespread attention in recent years and has become an important issue to be addressed especially by human resource managers who can by virtue of their jobs influence policies and procedures to ensure that the issue is addressed.

\section{The Objectives}

This paper explores the concept of workplace bullying to determine its exact nature. It looks at the features, sources, types and tactics of workplace bullying. It also examines the consequences of workplace bullying and how to deal with workplace bullying. In addition, it explores the relationship between work place bullying and organizational responses and attitudes, organization climate, 
gender and the self esteem of victims and finally gives recommendations for alleviating workplace bullying.

\section{Literature Review}

\subsection{The Concept of Workplace Bullying}

Workplace bullying involves the tendency of individuals or groups to use persistent aggressive or unreasonable behaviour against a co-worker or subordinate. The subject of workplace bullying is particularly difficult because, workplace bullies often operate within the established rules and policies of their organization and their society. Several different terms are used to describe the concept ranging from workplace bullying, harassment, workplace aggression, workplace victimization, mobbing, workplace abuse etc. Also, there is no generally agreed upon operational definition possibly usable in research and theory construction. However, several researchers have endeavoured to define it. As ${ }^{1}$ Rayner \& Hoel (1997) observes some literature define bullying from a legal perspective, while others view it from the harassment perspective. Some categorize all harmful boss behaviours and actions of mal intent directed at employees as bullying. Others separate behaviours into different patterns, labelling some of those behaviours as bullying.

${ }^{2}$ Namie and Namie (2009) asserts that bullying is persistent, nonphysical, and inappropriate treatment expressed towards one or more people, which occurs at least once a week for six months or more. They also suggest that workplace bullying involves repeated, healthharming mistreatment, verbal abuse, or conduct which is threatening, humiliating, intimidating, or sabotage that interferes with work or some combination of the three.

${ }^{3}$ Cortina, Magley, Williams, and Langhout (2001) sees workplace bullying or incivility as an act that may not be a blatant attempt to harm but nevertheless causes distress. Workplace bullying is most often a combination of tactics in which numerous types of hostile communication and behaviour are used. ${ }^{4}$ Lutgen-Sandvik (2010) states that workplace bullying is persistent verbal and nonverbal aggression at work that includes personal attacks, social ostracism and a multitude of other painful messages and hostile interactions. ${ }^{5}$ Mattice and Garman (2011) affirms that workplace bullying involves systematic aggressive communication, manipulation of work, and acts aimed at humiliating or degrading one or more individuals that create an unhealthy and unprofessional power imbalance between the bully and target(s), result in psychological consequences for targets and co-workers, and cost enormous monetary damages to an organization.

Bullying is a form of degradation, humiliation, intimidation and unfavourable treatment. ${ }^{6}$ Randall (1997) defines bullying as aggressive behaviour from the deliberate intent to cause physical or psychological distress to others.

James (1997) asserts that workplace bullying is an abuse of coercive power by either individuals in the internal workplace or external clients. Nevertheless, Idowu (2001) indicates that while behaviours involved in bullying are very common in everyday life, they result in serious harm when occurring on a regular basis. Victims perceive repeated and aggressive behaviours as bullying if such behaviour is perceived as being hostile, directed towards oneself especially where the victim is unable to defend himself.

\subsection{Features of Workplace Bullying}

Owing to the fact that workplace bullying takes place in very many different contexts and forms, the need arises to describe it using the key features the behaviours possess. Workplace bullying is a pattern of hostile messages and abusive behaviours persistently targeted at one or more persons in work settings that can involve work obstruction, public humiliation, verbal abuse, threatening behaviour, and multiple forms of intimidation. Amongst others, workplace bullying is characterized by repetition (occurs regularly), duration(endures), escalation(increasing aggression), power disparity (the target lacks the power to successfully defend themselves), and attributed intent.

Repetition - Workplace bullying is mostly a repeated behaviour though there are some singular events. It often involves numerous hostile interactions and transactions (e.g. verbal abuse and public humiliation coupled with social ostracism, work obstruction, and destructive gossip).

Duration- Again, workplace bullying occurs frequently and extends over long periods of time. Persistence makes bullying particularly harmful and corrosive, wearing down the targets' defenses, social support, and health.

Escalation - Adams and Crawford (1992) affirms that workplace bullying is escalatory, starting with occasional subtle, indirect insults or rude remarks and growing to more egregious and frequent types of humiliation, criticism, or verbal abuse.

Power Disparity- Workplace bullying is also associated with power disparity between perpetrators and targets, whether bullies are peers or supervisors. Power disparity can result from how bullying relentlessly wears down targets or can be structural in the form of the bullying boss. Power is often regarded as the psychological basis for bullying. Bullying is an abuse of the power relationship between the bully and the victim. It has to do with power, real or perceived and it is used to make people do things they do not have to, or stop them doing things they are entitled to do.

The perception is two sided with the bully thinking they possess power to proceed with inappropriate behaviour and the victim thinking the bully has the power to make them feel inadequate and intimidated. While target and witness resistance is common, and collective resistance can sometimes stop bullying, individual workers are often unable to end abuse once it has started. Power disparity becomes worse where multiple bullies work together or others indirectly support bullies' aggression. In such cases 
the resistance weakens and power disparity intensifies. Since power is the major element of bullying, managers and supervisors may sometimes be seen as bullies.

Power disparity in bullying situations is further enhanced by management's responses or non responses to complaints. ${ }^{7}$ Oloko (2001) observes that when targets speak out, they can be stigmatized, subjected to escalated abuse, or socially ostracized or the management may fail to take any action. ${ }^{8}$ Ireti (2007) adds that others who see these developments often become silent and unwilling to speak. Consequently, the power and oppression associated with workplace bullying affects not only the targets but the bullies, witnesses, and managers.

Attributed Intent- Workplace bullying brings in its wake humiliation, degradation, devaluation, loss of professional reputation and eventual exit of the target from the organization with all the concomitant, financial, career, health and psychological implications that one might expect from a protracted traumatizing experience.

\subsection{Reasons for Workplace Bullying}

A person bullies in the workplace for several reasons. One of such is to boost their self-esteem, ego and selfworth. Next is Power. Bullies could abuse their positions of power in order to gain control over their victims. There is also organizational culture. The morals and values dictate the workplace culture as well as expectations that are considered respectable behaviour among employees. Next is difference. Being new to an organization or considered "different" among counterparts may cause a person or group to become primary targets of workplace bullying. Another reason is perceived threat. Bullies may view an individual as a threat both personally and professionally. Workplace bullies, and bullies in general, seek validation and often struggle with personal emotional issues. Being bullied at the workplace can also become emotionally draining and lead to other detrimental effects such as health woes and severe depression. It can lead to resignation from the job because of the stress incurred or far worse, termination.

\subsection{Types of Workplace Bullying}

There different typologies of workplace bullying. Using the perpetrators typology, workplace bullying can be categorized as downwards, horizontal or upwards. Downward is that perpetrated by management or superiors to subordinates and it is regarded as the most common. Horizontal bullying involving peers bullying peers while upwards has to do with subordinates bullying managers.

Employers can also be bullies. Bad employers use bullying strategically to rid the workplace of good employees to avoid a legal obligation, such as paying some worker's compensation or claims. Again, bullying can be covert or overt, may be missed by superiors or known by many throughout the organization.

${ }^{9}$ Rayner et al (2001) put forward a typology of workplace bullying behaviours which many academic researchers have adopted with variations. The typology employs five different categories. The first involves threat to professional status - including belittling opinions, public professional humiliation, accusations regarding lack of effort, intimidating use of discipline or competence procedures. Second is threat to personal standing - including undermining personal integrity, destructive innuendos and sarcasm, making inappropriate jokes about target, persistent teasing, name calling, insults, and intimidation.

Third is isolation which includes preventing access to opportunities, physical or social isolation, withholding necessary information, keeping the target out of the loop, ignoring or excluding the target. Fourth is overwork which involves undue pressure, impossible deadlines, and unnecessary disruptions. Fifth is destabilisation which has to do with failure to acknowledge good work, allocation of meaningless tasks, removal of responsibility, repeated reminders of blunders, setting target up to fail, shifting goal posts without telling the target.

${ }^{10}$ Field (2001) gives another typology of workplace bullying according to forms of workplace bullying. Using this typology there is serial bullying in which the source of all dysfunction can be traced to one individual, who picks on one employee after another and destroys them, then moves on. It is one of the most common types of bullying. Next is secondary bullying where the pressure of having to deal with a serial bully causes the general behaviour to decline and sink to the lowest level. Again we have pair bullying which takes place with two people, one active and verbal, the other often watching and listening. In addition, there is gang bullying or group bullying involving a serial bully with colleagues. Gangs can occur anywhere, but flourish in corporate bullying climates. It is often called mobbing and usually involves scapegoating and victimisation.

Furthermore there is vicarious bullying in which two parties are encouraged to fight. It is the typical "triangulation" where the aggression gets passed around. Others types of workplace bullying include regulation bullying where a serial bully forces their target to comply with rules, regulations, procedures or laws regardless of their appropriateness, applicability or necessity. Another is residual bullying which is characterized by a situation in which after the serial bully has left or been fired, the behaviour continues. Next is legal bullying involving bringing a vexatious legal action to control and punish a person. It is one of the nastiest forms of bullying. There is also pressure bullying or unwitting bullying which has to do with having to work to unrealistic time scales and/or inadequate resources. Corporate bullying is another type of workplace bullying where an employer abuses an employee with impunity, knowing the law is weak and the job market is soft. Next is organizational bullying involving a combination of pressure bullying and corporate bullying. It takes place when an organization struggles to adapt to changing markets, reduced income, cuts in budgets, 
imposed expectations and other extreme pressures. More so there is institutional bullying where workplace bullying is entrenched and accepted as part of the culture. Furthermore, there is client bullying in which an employee is bullied by customers or those they serve. Lastly we have cyber bullying where information and communication technologies are used to support deliberate, repeated, and hostile behaviour by an individual or group, that is intended to harm others.

\subsection{Workplace Bullying Behaviours}

Workplace bullying mostly involves behaviours of a verbal nature and seldom includes physical violence. Bullying behaviours vary from ostracizing victims to spreading rumours and betraying trust. Bullying behaviours may be couched in humiliation and hazing rites and iterative programmes or protocols framed as being in the best interests of employee development and coaching. As ${ }^{11}$ Smith (1999) observes some forms of bullying manifest from legitimate or expert power through behaviours like verbal reprimands or abuse, allocation of undesirable work duties, and tighter and closer supervision. Workplace bullying can include such tactics as verbal, nonverbal, psychological, physical abuse and humiliation.

The most common tactics of workplace bullies include false accusations, staring, glaring unjustly discounting victim's thoughts or feelings at meetings, silent treatment, icing out and separating them from others, mood swings, making up rules on the fly, discrediting, harsh and constant criticism of victims, multiple standards, destructive rumours or gossip, encouraging people to turn against victims, victims being singled out and isolated from other co workers, yelling, screaming, throwing tantrums, stealing credit for work done, abusing evaluation processes, lying, retaliation, verbal put-downs/insults (based on gender, accent, age or language, disability), assigning undesirable work as punishment, creating unrealistic demands and sabotage.

\subsection{Consequences of Workplace Bullying}

Workplace bullying has several costs and consequences for both employers and employees some of which are financial and psychological. The human resources of any organization are very crucial to organization and managers understand that workers are the most important contributors to the efficient achievement of organization success. Negative effects and consequences are not limited to the targeted individuals, and lead to a decline in employee morale and company culture.

The major factors of production include land, capital, human resources, materials, time, and information, that is, capital, natural and human resources. Capital and natural resources are passive agents of development, but human resources are active agents since they alone are capable of accumulating capital, exploiting natural resources and combining them with themselves to produce goods and render services.

Agreeing with this idea, ${ }^{12}$ Giwa (1990) comments that of all the resources an organization or nation needs human resources are the most important. Human beings make things happen and efficient human beings make things happen efficiently. Apart from being the most important factor of production, human beings are themselves the most dynamic, complex and unpredictable resource. They combine other resources with themselves, change their constituent and mix them in various proportions to produce goods and render the services, which they themselves consume.

The cost of bullying to an organization is enormous. It includes illness among the workforce resulting in loss in employment, replacement costs of those who leave as a result of being bullied or witnessing bullying, the cost of litigation should victims bring suits against the organization, drop in productivity and higher levels of absenteeism. Not managing conflict and bullying type behaviours effectively brings large financial costs and erodes organization human resources asset. Low productivity is another major problem usually attributable to workplace bullying. A similar consequence of workplace bullying is absenteeism. Studies such as ${ }^{13}$ Oloko (2001) and ${ }^{14}$ Awe (2004) indicate that a high level of absenteeism is a resultant effect of stressful working conditions. Other studies also identify high turnover rate as a major consequence of workplace bullying. Employee turnover is quite expensive for organizations especially because organizations invest a lot in their human resource in terms of training and development all of which may go to waste where the staff members do not stay. Other consequences include employee poor morale and low levels of motivation. Again there are issues of litigation, and possible workers' compensation claims. There are also a wide range of resultant effects like feelings of helplessness, isolation, withdrawal, different types of fear, anxiety, depression, lack of concentration, low morale, low selfesteem, poor job performance all of which have negative consequences for organizations effectiveness. Bullying creates a hostile work environment or sometimes the loss of a loyal or good employee.

\subsection{Gender and Workplace Bullying}

Workplace bullying is usually not based on position or gender. ${ }^{15}$ King (1996) reports that while victims of workplace bullying comprise all levels, professions, and genders, most of them are females. A 2010 survey by the Workplace Bullying Institute suggests that women can be nastier bullies than men, at the workplace and that womanon-woman harassment is on the rise. The study affirms that thirty-five percent of Americans reported being bullied at work and that women make much nastier office bullies than men. The same study notes that workplace bullying is four times more common than sexual harassment and racial discrimination. A probable cause of the higher percentage of female bullies could be that girls are taught to be critical of each other from adolescence, and it is particularly 
vicious among working women who often feel the need to be hyper-aggressive to get ahead especially in maledominated occupations and environments. Again, women are more likely to feel threatened by other competent women. They also have a tendency to get unfairly vindictive with each other and hold long grudges often about minor things.

${ }^{16}$ Aluko (2006) affirms that women sabotage the careers of other women by being unsupportive. The study posits that multiple standards is more common with females and highlights "rope ladders," where women climb to senior positions, then promptly haul up the ladder right behind them. In addition ${ }^{17}$ Onadeko (2000) opines that while some women tactically avoid helping other women in their careers, others resort to passive-aggressive behaviours to protect their interests. ${ }^{8}$ Ireti (2007) suggests that women are their own worst enemies because women usually fail to accord fellow women leaders as much respect as they would male leaders. ${ }^{18}$ Aremu (2001) observes that situations of female bosses bullying their staff (even the males) are happening more often. However, because men are seen as the problem-solvers while women are viewed as the fairer sex it is culturally confronting for a man to discuss being bullied by a woman. Workplace bullying by female bosses also tends to be under-reported because men who do complain about being bullied by a woman are likely told to "man up" and deal with it. Therefore men tend to leave rather than deal with the problem, a situation that is detrimental to the organisation as it loses the talent and is likely to keep on making the same mistakes. Unfortunately, women are also more likely to become targets of workplace bullying than men. Studies conducted by the Workplace Bullying Institute found a strong gender dynamic at play with $62 \%$ of workplace bullies being male, and women comprising $58 \%$ of workplace bullying targets.

\subsection{Dealing with Workplace Bullying}

Victims of workplace bullying can deal with it in several ways. One of such is to seek the advice of trusted mentors who may have dealt with such situations before. Another may be to (where possible) confront the bully in a professional manner without threatening one's physical safety. Care must be taken by the victim not to allow the bully to intimidate him/her. Victims must also ensure that their jobs are not only always done but that they are well done. This can be quite effective because refusing to let the workplace bully achieve the aim of wanting the victim to fail defeats them.

In addition victims and targets must make sure that superiors are aware of their work since bullies often try to spread the word that the victims are not doing their jobs well and may report even the smallest infractions. Furthermore targets of workplace bullying must ensure that they are not isolated from their colleagues. It is important to bear in mind that regaining power and control over the situation is fundamental to coping with workplace bullying. Consequently the need arises to back and follow up all information and conversations in writing. This can be fruitful and beneficial in bringing claims against a workplace bully.

In addition, victims can reduce the amount of personal information individuals have on them in the workplace as this can significantly reduce criticism and allegations. Victims can also try to familiarize themselves with possible anti-bullying procedures associated with the organization for a better understanding of the reporting process against workplace bullies. Allegations of workplace bullying are often difficult to prove. Victims often do not possess the self-confidence and self-esteem to lodge a complaint and may feel powerless to report due to fear of job dismissal. Organizations must therefore encourage employees to report bullying.

\section{Statement of Hypotheses}

Arising from the review of literature the study postulated the following research hypotheses for testing:

$\mathrm{H}_{\mathrm{O} 1}$ : There is no significant relationship between gender and workplace bullying.

$\mathrm{H}_{\mathrm{O} 2}$ : There is no significant relationship between perceived

organizational responses and willingness to make complaints on workplace bullying.

$\mathrm{H}_{\mathrm{O} 3}$ : There is no significant relationship between perceived

organization culture and level of workplace bullying.

$\mathrm{H}_{\mathrm{O} 4}$ : There is no significant relationship between self esteem and workplace bullying.

\section{Methodology}

This study was aimed at examining the exact nature of workplace bullying and its consequences. Questionnaires were administered in a field survey spanning two months between July and August 2013. The survey consisted of 300 participants selected from different organizations including the public education, finance, communications and health sectors in Lagos Nigeria. The total sample size of the present study is arbitrarily assigned as one percent of the population. The applied sampling procedure is purposive sampling. The response rate was $280(93.3 \%)$ of which 152 (54\%) were men and 128 (46\%) were women.

The survey sought information on features, sources, targets, experiences and organization responses to workplace bullying using the Workplace Bullying Institute's (WBI) questionnaire template with a little adaption for the Nigerian environment. This is because the organization has not only extensive experience with bullying but past studies of bullying. The study measured workplace bullying using variables identified by the workplace-bullying institute. A pilot study was conducted among with 30 respondents and a few modifications were carried out. Added to demographic information, the survey inquired about bullying experiences relating to witnessing, 
experiencing, or perpetrating bullying, sources of bullying, perceived reactions and support for bullying as well as organizational responses to reported bullying. Chi square statistics was used to test the hypotheses. The reliability of the instrument was determined using Cronbach's alpha and Pearson correlation. The reliability co-efficient of the modified instrument after the pilot survey yielded an $\mathrm{r}=$ 0.734 cronbach alpha while Pearson correlation was 0.724 $(p<0.001)$ indicating that the instrument was reliable.

\section{Findings}

\subsection{Features of Workplace Bullying}

The study examined workers views on what to them constitutes bullying on their jobs. Respondents identified features like persistence and length of time, the different categories of perpetrators and witnesses as well as the attitudes and reactions to bullying. Respondents were also given items measuring exposure to negative acts. $71.8 \%$ of the respondents indicated that workplace bullying involves particular types of behaviour having to do with concealing crucial information. $31 \%$ of the respondents admitted that they have been targets of workplace bullying at one time or the other. Furthermore 52\% of these targets felt their work productivities and performances were negatively affected because their bullies purposely held back information from them to make them perform poorly on their jobs. Others

$32 \%$ said that their bosses repeatedly checked their works and even the completion of important assignments were never appreciated. $42 \%$ observed that their bullies devalued their work and assigned them tasks that were clearly outside their job descriptions. Again $45 \%$ of the respondents observed that their professional opinions and views were never valued and they received hostile answers to questions. $35 \%$ of the respondents reported that they were often assigned tasks with impossible deadlines by their bullies. 14\% reported that their bullies spread rumours about their personal life.

\subsection{Sources of Bullying}

The respondents were asked to indicate the sources of bullying. $52 \%$ of the respondents identified the sources of bullying as supervisors and bosses while 32\% identified peers as sources of bullying, $10 \%$ identified their bullies as subordinates and only $16 \%$ indicated that it is usually combination of bosses, peers and subordinates. The result of this study therefore suggests that while there are other sources of bullying in the workplace, supervisors and bosses constitute the most common sources of bullying in the workplace. The results of this study show superiors and bosses being the more common sources of bullying. Results of previous studies in this area tend to go both ways. For instance while the findings of studies like ${ }^{19}$ Namie (2003) and ${ }^{20}$ Okorodudu (2008) support those of this study that supervisors and bosses are the most commonly reported bullies that of ${ }^{21}$ Keashly and Jagatic (2000) indicates that a
Michigan study reports equal rates for bosses and co workers.

\subsection{Organizational Attitudes and Responses to Workplace Bullying}

The attitudes, responses and interventions of organization top management is crucial in dealing with workplace bullying. Studies like ${ }^{22}$ Ojo (1998), ${ }^{23}$ Lutgen Sandvik (2006) and ${ }^{14}$ Awe (2004) found that most targets of workplace bullying felt their employers took no actions when the mistreatments were reported. The problems were not resolved rather the complaints were either ignored or top management sided with the bullies. For this study 59\% of the respondents felt that top management did not do much about the complaints while $28 \%$ indicated that rather than things getting better for them it became worse, a situation that discouraged other co-workers. Only13\% of the respondents felt that organizational actions made a positive difference. This implies that more often than none there is seeming inaction by management when cases of workplace bullying are reported. Top management may not act (or may not be seen as acting) and several explanations can be adduced for this situation. For instance ${ }^{24}$ Namie $(2004 ; 2007)$ observes that some inertia may arise from lack of knowledge on the idea of bullying. Also, to ensure employee privacy, negative sanctions against or investigations of aggressive workers are usually covered and not made public. In the same vein, ${ }^{25}$ Lutgen-Sandvik (2008) affirms that top management may hold firmly to a classical chain-of-command and interfering with line supervisors' decisions or actions may look practically heretical.

It must be noted here however, that when employees speak out about bullying and top management is not seen as doing anything about it organizational climates can develop where bullies harass other without regard.

Organisation culture therefore sometimes encourages workplace bullying by indoctrinating workers with the mentality of its being acceptable. Organizations must therefore build a culture of respect indicating positive behaviours expected from organization members. Also top management must constantly reinforce positive behaviours and provide training in mediation and conflict resolution.

$75 \%$ of the respondents of this study indicated that bullies usually receive support either actively or passively from their peers. Therefore if the bully is a boss more support tends to come from officers superior to the target (like managers) and peers with the bully. For bullies who are subordinates the support mostly emanates from subordinates and for peer bullies their support came mostly from other peers.

\subsection{Effects of Workplace Bullying}

Workplace bullying has significant effects and costs for both workers and organizations. As earlier mentioned in the literature review, workplace bullying is associated with 
health and relationships effects ranging from insomnia, stress, absenteeism, job dissatisfaction, low morale, low motivation, low self-esteem, depression and labour turnover. ${ }^{22}$ Namie (2007) observes that the damage inflicted by bullying can often be worse than that from sexual harassment because workplace bullying is personalized and usually touches on the target's deepest insecurities. 75.6\% of the respondents indicated that they felt at least one of the effects identified above as a result of the bullying they experienced. Again, $63.4 \%$ of them indicated that effects from bullying bosses and supervisors are more negative and have more far reaching effects.

\subsection{Gender and Workplace Bullying}

This study also investigated possible gender dynamics of workplace bullying to explore whether there are gender differences in bullies, and targets. ${ }^{26}$ A 2007 study of the Workplace Bullying Institute (WBI) reports that while bullies are of both genders, women bullies tend to disrupt relations or pit worker against worker.

The study found a strong gender dynamic at play with $62 \%$ of reported workplace bullies being males, while women comprised $58 \%$ of targets. ${ }^{8}$ Ireti (2007) suggests that women are more likely to become targets of workplace bullying than men. This could be because women are often considered nurturing and passive-aggressive both inside and outside the workplace, making it easier for them to become targets.

This present study also found that while more women than men reported being targets of workplace bullying (females 71\%); males 29\%), males were more often reported as bullies than were females (males 67\%; females $33 \%$ ). The respondents however suggested that as more women are gaining leadership positions in the workforce, the numbers of female workplace bullies are increasing. This supports the finding of ${ }^{17}$ Onadeko (2000) which found the number of female bullies rising and suggests that the higher number of female bullies in the workplace can be attributed to the fact that women feel the need to be hyper-aggressive to get ahead in male-dominated occupations and environments.

$62 \%$ of the respondents in this study opined that female bullies tend to be less reported. A possible explanation for under-reporting female bullies is that while situations of females (especially bosses) bullying their male staff is happening more often, it is unusual for men to report being bullied by females. Men who are bullied by their female managers is an area of workplace bullying that tends to receive less attention even though the effects are just as devastating. Men are viewed as the problem-solvers while women are viewed as the fairer sex so it is culturally confronting (especially in Africa) for a man to report being bullied by a woman. According to Planned Parenthood, adjectives associated with masculinity are competitive, non- emotional, tough skinned and aggressive. Whereas, words used to describe femininity include passive, sensitive, emotional, weak and nurturing. Consequently men tend to suffer in silence or leave rather than deal with the problem. This is detrimental to the organisation because it brings about a high level of employee turnover and loss of talents. $54.3 \%$ of the respondents in this study indicate that women sometimes sabotage the careers of other women by being unsupportive. Again, 62\% suggested that woman-onwoman bullying is also on the rise. The effect of female bullies is equally as brutal as their male counterparts. Females are more likely to feel threatened by other competent women and therefore be more bitchy and vengeful too. $56 \%$ of the respondents indicated that males are generally more straightforward and pragmatic, and therefore easier to work with while women get unfairly vindictive with each other and hold long grudges often about minor things. Men would rather push people around to show hierarchy.

$68 \%$ of the respondents indicated that women can be nastier work place bullies than men. A possible reason for this is the belief that girls are taught to be critical about each other from adolescence. $62 \%$ of the respondents felt that the bullying seems particularly vicious among working women especially where both the perpetrator and the victim are women. They identified tactics employed in women to women bullying to range from lying, playing favourites, gossiping to badmouthing, being forced to stay late, being given extra work compared with the amount colleagues are given, not being allowed to take holidays, not being believed if sick leave is taken, and not getting a fair increase in salary and other indirect tactics.

\subsection{Test of Hypotheses}

\section{Hypothesis 1}

HO1: There is no significant relationship between gender and workplace bullying.

Table 1. Relationship between gender and workplace bullying.

\begin{tabular}{ccccc}
\hline $\mathbf{O}$ & $\mathbf{E}$ & $\mathbf{O - E}$ & $(\mathbf{O}-\mathbf{E})^{2}$ & $(\mathbf{O}-\mathbf{E})^{2} / \mathbf{E}$ \\
\hline 180 & 93.3 & 86.7 & 7516.89 & 80.57 \\
58 & 93.3 & -35.3 & 1246.09 & 13.36 \\
42 & 93.3 & -51.3 & 2361.69 & 28.21 \\
280 & 280 & & & 122.14 \\
\hline
\end{tabular}

$\mathrm{X}^{2}$ (cal.) $=122.14, \mathrm{df}=2 . \quad \mathrm{X}^{2}$ tab at 0.05 level of significance $=5.99$. Since the calculated $X^{2}$ of 122.14 is greater than $\mathrm{X}^{2}$ table value, we reject the null hypothesis (Ho) and accept the alternative hypothesis $\left(\mathrm{H}_{1}\right)$. This implies a significant relationship between gender and workplace bullying. Women tend to be more workplace bullies than men. Women often employ double standards and rope ladders, where women climb to senior positions are quickly hauled up the ladder right behind them. While some tactically avoid helping other women in their careers, others can resort to passive-aggressive behaviour to protect their interests. Women also appear to be at greater risk of 
becoming bullying targets and more women report being targets and when the bully is a woman her target is more likely to be a woman as well. Higher prevalence rates for being threatened, bullied, or harassed are usually identified for women.

\section{Hypothesis 2}

$\mathrm{H}_{\mathrm{O} 2}$ : There is no significant relationship between perceived organizational responses and willingness to make complaints on workplace bullying.

Table 2. Relationship between organizational responses and complaints of workplace bullying.

\begin{tabular}{ccccc}
\hline $\mathbf{O}$ & $\mathbf{E}$ & $\mathbf{O - E}$ & $(\mathbf{O - E})^{2}$ & $(\mathbf{O - E})^{2} / \mathbf{E}$ \\
\hline 159 & 93.3 & 65.7 & 4316.49 & 46.24 \\
67 & 93.3 & -26.3 & 691.69 & 7.41 \\
54 & 93.3 & -39.3 & 1544.49 & 16.55 \\
280 & 280 & & & 70.2 \\
\hline
\end{tabular}

$\mathrm{X}^{2}$ (cal.) $=70.2, \mathrm{df}=2 . \mathrm{X}^{2}$ tab at 0.05 level of significance $=5.99$. Since the calculated $X^{2}$ of 70.2 is greater than $\mathrm{X}^{2}$ table value, we reject the null hypothesis (Ho) and accept the alternative hypothesis $\left(\mathrm{H}_{1}\right)$. This implies a significant relationship between organizational attitudes and responses and the willingness of workers to report workplace bullying. Only a few of the respondents indicated that organization management see workplace bullying as a serious problem arising from the fact that targets most often attempt unsuccessfully to get management to respond to it decisively. Leadership commitment predicts success with any organization change initiative. The importance of top management commitment to dealing with workplace bullying cannot be over emphasized.

\section{Hypothesis 3}

$\mathrm{H}_{\mathrm{O} 1}$ : There is no significant relationship between perceived organization culture and level of workplace bullying.

Table 3. Relationship between perceived organization culture and level of workplace bullying

\begin{tabular}{ccccc}
\hline $\mathbf{O}$ & $\mathbf{E}$ & $\mathbf{O - E}$ & $(\mathbf{O}-\mathbf{E})^{\mathbf{2}}$ & $(\mathbf{O - E})^{\mathbf{2}} / \mathbf{E}$ \\
\hline 129 & 93.3 & 35.7 & 1274.49 & 13.66 \\
105 & 93.3 & 11.7 & 136.89 & 1.47 \\
46 & 93.3 & -47.3 & 2237.29 & 23.98 \\
280 & 280 & & & 33.11 \\
\hline
\end{tabular}

$\mathrm{X}^{2}$ (cal.) $=33.11, \mathrm{df}=2 . \mathrm{X}^{2}$ tab at 0.05 level of significance $=5.99$. Since the calculated $X^{2}$ of 33.11 is greater than $\mathrm{X}^{2}$ table value, we reject the null hypothesis (Ho) and accept the alternative hypothesis $\left(\mathrm{H}_{1}\right)$. This implies a significant relationship between perceived organization culture and level of workplace bullying. A change must be initiated in corporate culture on workplace bullying and this can only be achieved if organization top management make it a top priority.

\section{Hypothesis 4}

HO1: There is no significant relationship between self esteem and workplace bullying.

Table 4. Relationship between self esteem and workplace bullying.

\begin{tabular}{ccccc}
\hline $\mathbf{O}$ & $\mathbf{E}$ & $\mathbf{O - E}$ & $(\mathbf{O - E})^{2}$ & $(\mathbf{O - E})^{2} / \mathbf{E}$ \\
\hline 143 & 93.3 & 49.7 & 2470.09 & 26.48 \\
88 & 93.3 & -5.3 & 28.09 & 0.30 \\
49 & 93.3 & -44.3 & 1962.49 & 21.03 \\
280 & 280 & & & 47.81 \\
\hline
\end{tabular}

$\mathrm{X}^{2}$ (cal.) $=47.81, \mathrm{df}=2 . \quad \mathrm{X}^{2}$ tab at 0.05 level of significance $=5.99$. Since the calculated $X^{2}$ of 47.81 is greater than $\mathrm{X}^{2}$ table value, we reject the null hypothesis (Ho) and accept the alternative hypothesis $\left(\mathrm{H}_{1}\right)$. This implies a significant relationship between self esteem and workplace bullying. While workplace bullying may not be a blatant attempt to harm, it nevertheless causes distress. Victims of workplace bullying often exhibit lower levels of self-esteem and feel that their personalities caused them to be bullied. The study concludes that a high prevalence of workplace-bullying results in decreased levels of selfesteem.

\section{Recommendations}

Workplace bullying is and will continue to be a costly problem for employers and employees. Arising from the findings of this study as discussed above, we recommend that there is need for organization stakeholders to that ensure workplace bullying is tackled in all areas including organization policies and procedures as well as legislation. Workplace bullying must be addressed sufficiently. The study underscores the importance of upper management's responses to bullying. Doing nothing is not a neutral act when workers ask for help; when nothing is done, organizations inadvertently becomes bullies' accomplices. When left unattended, bullying can spread like a contagion, becoming the accepted, albeit painful, norm for interactions. The importance of top management support in this regard cannot be overemphasized. Codes of conduct should be developed on suitable workplace behaviours and appropriate procedures for reporting and investigating allegations of workplace bullying should be established in addition to grievance procedures for employees. Organizations must review organization and work cultures accommodating and or contributing to workplace bullying. Adequate reporting mechanisms must be put in place between the human resource department and top management to lodge complaints on workplace bullying.

Furthermore as a proactive measure towards preventing or at least reducing workplace bullying, education in workplace bullying could be introduced in institutions of higher learning. This will prepare even new entrants into the labour for to be able to quickly identify workplace 
bullying and know how to address it. Human resource practitioners must be trained in investigation processes to ensure that any reported cases are investigated properly. Finally, the need for empirical studies on bullying at work is very crucial.

\section{Conclusion}

This study concludes that workplace bullying is very real in work organizations and it involves one or more individuals. Its occurrence is both regular and persistent and its consequences include low levels of motivation, absenteeism, high level of labour turn-over and job dissatisfaction. etc. Owing to the seriousness of workplace bullying, action needs to be taken by all organization stakeholder to ensure that it is adequately addressed.

\section{References}

[1] Rayner, C., and Hoel, H.(1997).Workplace bullying: Myth or reality-can we afford to ignore it? Leadership and organizational development journal, 18,211-214

[2] Namie, G., \& Namie, R. (2009). Workplace bullying: Causes, consequences, and corrections. In P. LutgenSandvik \& B. D.Sypher (Eds.), Destructive organizational communication: Processes, consequences, and constructive ways of organizing (pp. 27-52). NewYork: Routledge/Taylor \& Francis.

[3] Cortina, B. M, Magley. R.S, Williams. O.T and Langhout P. S. (2001) Exploring Workplace Bullying: A review of structures and processes in the workplace. Human Relations, $73(14), 430-452$.

[4] Lutgen-Sandvik, P. (2010). The communicative cycle of employee emotional abuse: Generation and regeneration of workplace mistreatment. Management Communication Quarterly, 16(4), 471-501. doi: 10.1177/08933189032 1627.

[5] Mattice and Garman (2011) Building a culture of respect:Managing bullying at work (pp. 135-154). London: Taylor \& Francis.

[6] Randall (1997) Theoretical approaches to the study of bullying at work. International journal of manpower, 20 , 11-15.

[7] James, D. (1997), 'Jekyll, Hyde and Other Management Types', Business Review Weekly, 1 December, p. 86.

[8] Idowu O. R. (2001) 'Bullying in the Workplace', Journal of Applied Social Psychology, vol. 7, no. 35, pp. 22-26.

[9] Adams, A., Crawford, N.(1992). Bullying at work: How to confront and overcome it. London: virago press.

[10] Oloko (2001) Workplace Bullying: Curing the Cancer of the Workplace. Public personnel management, 30(3), 269-286.

[11] Ireti (2007) Recognition of workplace bullying: A qualitative study of women targets in the public sector. Journal of Applied Social Psychology, 16, 119-135.
[12] Rayner C, Hoel H, Cooper C. L, (2001) Workplace Bullying: What we know, who is to blame and what can we do?

[13] Field, Tim (2001) Bullying: what is it?

[14] Smith J. F, (1999) Prevalence and forms of bullying among business professionals: A comparison of two different strategies for measuring bullying. Journal of Work and Organizational Psychology, 16(3), 213-223.

[15] Giwa R.F. (1990), “Clean Wage Option Implication for Management /Employer Relations", Human Resources Management,Vol.9 No.1

[16] Awe. K.P. (2004)Violence at Work:The Brutal Truth. Journal of work and organizational psychology, 14,39-53.

[17] King, D. 1996, 'Bullying — a Workplace Nightmare', Proctor, September

[18] Aluko M. F. (2006) Bully Insight - How to Resist, Challenge and Combat Workplace Bullying', 26th June, p. 10

[19] Onadeko, F.B (2000), 'Women Employment and Trade Unions in Nigeria" in Sokunbi, O et'al (eds): Women and Trade Union in Nigeria. NPS Educational Publishers Ltd. S.W. Ibadan

[20] Aremu Issa (1999) 'Organisation Structure in Nigeria: Implications for women participation" in Sokunbi, O et'al (et in Women and Trade Union in Nigeria. NPS Educational Pu blishers Ltd. S.W. Ibadan

[21] Namie, G. (2003). The WBI 2003 report on abusive workplaces. Retrieved October 19, 2003, from www.bullyinginstitute.org

[22] Okorodudu (2008) Bullying in the Workplace: Prevalence, perception, degree, and impact. Journal of Management Studies, 41(3), 342-3686.

[23] Keashly, L., \& Jagatic, K. (2000). The nature, extent and impact of emotional abuse in the workplace: Results of a statewide survey. Paper presented at the Academy of Management Conference, Toronto, Canada.

[24] Ojo. F, (1998): Human Resources Management Theory and Practice. Panaf, Lagos.

[25] Lutgen -Sandvik (2006) Emotional abuse in the workplace: Conceptual and empirical issues. Journal of emotional abuse, 1(1),85-117.

[26] Namie, G. (2004). Workplace bullying: Escalated incivility. Ivey Business Journal, 68(2), 1-6.

[27] Namie, G. (2007). The challenge of workplace bullying. Employment Relations Today, 34(2), 43-51.

[28] Lutgen - Sandvik (2008) Work place violence and workplace aggression: evidence on their relative frequency and potential causes Aggressive behavior, 22,161-73.

[29] Namie, G. (2007b). The Workplace Bullying Institute 2007 U.S. Workplace Bullying Survey. http://bullyinginstitute.org/wbi-zogby2.html 